\title{
Clarifying a Competitive Crystallization Mechanism of Upconversion Luminescent Oxyfluoride Glass Ceramics by
}

\section{Solid-State NMR Spectroscopy}

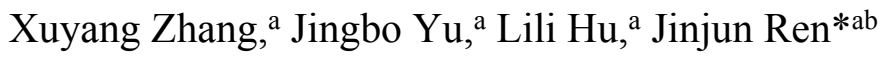 \\ ${ }^{a}$ Key Laboratory of Materials for High Power Laser, Shanghai Institute of Optics and Fine Mechanics, Chinese Academy of \\ Sciences, Shanghai 201800, P. R. China \\ ${ }^{b}$ Center of Materials Science and Optoelectronics Engineering, University of Chinese Academy of Sciences, Beijing 100049, \\ P.R. China
}

Email: Jinjunren@s,siom.ac.cn

\section{Experimental details of solid-state NMR experiments}

The ${ }^{139} \mathrm{La}$ NMR spectra were obtained by static wideband uniform-rate smooth truncation QCPMG (WURST-QCPMG) method $^{1}$ on a $4 \mathrm{~mm}$ MAS NMR probe, employed with a WURST-80 pulse sequence and an 8 step phase cycle. The resonance frequency was $70.6 \mathrm{MHz}$ and the relaxation delay was $0.2 \mathrm{~s}$. The excitation and refocusing pulses were $50 \mu$ s (nutation frequency $8.13 \mathrm{kHz}$ ) and the sweep frequency was $700 \mathrm{kHz} / \mathrm{ms}$. Each spectra slice was excited twice in opposite directions to compensate for line shape distortions. In order to record the full ${ }^{139} \mathrm{La}$ spectra, multiple spectra slices were measured with an excitation frequency offset of $252 \mathrm{kHz}$ and co-added. The chemical shifts of ${ }^{139} \mathrm{La}$ are referenced to $\mathrm{La}\left(\mathrm{NO}_{3}\right)_{3}(1 \mathrm{M})$.

The heteronuclear dipole-dipole interactions were measured using rotational echo double resonance (REDOR) and rotational echo adiabatic passage double resonance (REAPDOR) techniques. By applying $\pi$ pulses or adiabatic mixing pulses to the non-observed I-spins, the dipole-dipole interactions averaged out by MAS can be recoupled. These experiments generally contain two part, one is the REDOR intensity $\mathrm{S}$ measured under the dipolar interactions between observed nuclei $\mathrm{S}$ and influenced nuclei $\mathrm{I}$, the other is the echo intensity $\mathrm{S}_{0}$. Then the normalized difference signal intensity $\Delta \mathrm{S}=\left(\mathrm{S}_{0}-\mathrm{S}\right) / \mathrm{S}_{0}$ was calculated and plotted with the increase of dipolar evolution time $\mathrm{NT}_{\mathrm{r}}(\mathrm{N}$, the number of rotor cycles and $\mathrm{T}_{\mathrm{r}}$, the rotor period) to obtain the REDOR (REAPDOR) curve. In the ${ }^{27} \mathrm{Al}\left\{{ }^{19} \mathrm{~F}\right\}$ and ${ }^{23} \mathrm{Na}\left\{{ }^{19} \mathrm{~F}\right\}$ REDOR experiments, where the dipolar dephasing of observed $\mathrm{S}$ spins $\left({ }^{27} \mathrm{Al}\right.$ and ${ }^{23} \mathrm{Na}$ ) occurs in the local field of ${ }^{19} \mathrm{~F}$ spin (spin moment $\mathrm{I}=1 / 2$ ), the REDOR sequence of Gullion and Schaefer was chosen. ${ }^{2,3}$ The second moment $M_{2}{ }^{\mathrm{Al}-\mathrm{F}}$ and $M_{2}{ }^{\mathrm{Na}-\mathrm{F}}$ values characterizing the average dipolar coupling strengths were obtained by fitting the initial valid region $\left(0 \leq \Delta S / S_{0} \leq\right.$ 0.2-0.3) of REDOR curves using the following equation: ${ }^{4,5}$

$$
\frac{\Delta S}{S_{0}}=\frac{4}{3 \pi^{2}} M_{2}^{S I}\left(N T_{r}\right)^{2}
$$


In the ${ }^{19} \mathrm{~F}\left\{{ }^{23} \mathrm{Na}\right\}$ REDOR experiments, several additional complications appear, ${ }^{6}$ since the dipolar dephasing of observed S spins $\left({ }^{19} \mathrm{~F}\right)$ occurs in the local field of I spins $\left({ }^{23} \mathrm{Na}\right)$ with spin moment $\mathrm{I}=3 / 2 .{ }^{7,8}$ The calculation of $M_{2}{ }^{\mathrm{F}-\mathrm{Na}}$ values can be extended to $\mathrm{I}=3 / 2$ system by using the following expression within the valid range $\left(0 \leq \Delta S / S_{0} \leq\right.$ $0.2-0.3):^{9}$

$$
\frac{\Delta S}{S_{0}}=\frac{1}{15 \pi^{2}}(2+18 f) M_{2}^{\mathrm{SI}}\left(N T_{r}\right)^{2}
$$

where the efficiency factor $f(0 \leq f \leq 1)$ represents the dipolar coupling degree of I spins to S spins in the non-central Zeeman states still affects the REDOR response. ${ }^{8,} 9$ The $f$ values were obtained from experimental conditions and measured ${ }^{23} \mathrm{Na}$ second-order quadrupolar effects (SOQE) data with the help of SIMPSON simulation. ${ }^{10}$ The experimental $M_{2}$ values can be compared with the theoretical calculation results according to the crystal models using the van Vleck equation: ${ }^{11}$

$$
M_{2}^{\mathrm{SI}}=\frac{4}{15}\left(\frac{\mu_{0}}{4 \pi}\right)^{2} \mathrm{I}(\mathrm{I}+1) \gamma_{S}^{2} \gamma_{I}^{2} \hbar^{2} \sum r_{\mathrm{SI}}^{-6}
$$

where $\gamma_{\mathrm{I}}$ and $\gamma_{\mathrm{S}}$ represent the gyromagnetic ratios of I and S nuclei, respectively, and $r_{\mathrm{SI}}$ is the internuclear distance between them. In the ${ }^{19} \mathrm{~F}\left\{{ }^{27} \mathrm{Al}\right\}$ and ${ }^{19} \mathrm{~F}\left\{{ }^{139} \mathrm{La}\right\}$ REAPDOR experiments, ${ }^{12}, 13$ where the local dipolar dephasing field is created by spin $5 / 2\left({ }^{27} \mathrm{Al}\right)$ or $7 / 2\left({ }^{139} \mathrm{La}\right)$ nuclei, a continuous irradiation lasting $1 / 3$ of the rotor period was used to generate a maximum difference signal. ${ }^{14}$ All the detailed experimental parameters of REDOR and REAPDOR experiments are summarized in Table S1.

The triple-quantum magic angle spinning (TQMAS) experiments were done to obtain high-resolution ${ }^{23} \mathrm{Na}$ spectra, using the $\mathrm{z}$ filtering pulse sequence ${ }^{15,16}$ and conducting on a $4 \mathrm{~mm}$ MAS probe. The resonance frequency was 132.3 $\mathrm{MHz}$ and spinning rate was $12.0 \mathrm{kHz}$. The first strong pulse of $5.4 \mu \mathrm{s}$ was used to excite the maximum triple-quantum coherence, which was then transferred to zero-quantum coherence by the second pulse of $1.8 \mu$ s (nutation frequency 64.1 $\mathrm{kHz}$ ). The soft pulse of $11 \mu \mathrm{s}$ was used to obtain observable single-quantum coherence (nutation frequency $9.9 \mathrm{kHz}$ ). The obtained isotropic chemical shifts $\delta_{C S} S^{i s o}$ and second-order quadrupolar effects $(S O Q E)$ values are summarized in Table S3.

Static spin echo decay measurements were done to detect the distribution of ${ }^{19} \mathrm{~F}$ and ${ }^{23} \mathrm{Na}$ nuclei. For ${ }^{19} \mathrm{~F}$, the $90^{\circ}$ and $180^{\circ}$ pulse lengths were 2 and $4 \mu \mathrm{s}$, respectively, and the relaxation delay was $30 \mathrm{~s}$. For ${ }^{23} \mathrm{Na}$, the $90^{\circ}$ and $180^{\circ}$ pulse lengths of 10.3 and $20.6 \mu$ s were used (nutation frequency $11.3 \mathrm{kHz}$ ), respectively, and the relaxation delay was $0.5 \mathrm{~s}$. In these experiments, several spin echo spectra are obtained with the systematically increase of dipolar evolution time. Then, the spin echo amplitudes were plotted as a function of dipolar evolution time to yield decay curves. The homonuclear dipolar second moment $M_{2}^{\text {homo }}$ can be obtained by fitting these curves according to the following Gaussian function: ${ }^{17}$

$$
I_{\left(2 t_{1}\right)} / I_{0}=\exp \left\{-\left(2 t_{1}\right)^{2} M_{2}^{\text {homo }} / 2\right\}
$$

where $I_{\left(2 t_{1}\right)}$ represents the intensity of spin echo at evolution time $2 t_{1}, I_{0}$ is a constant. The obtained $M_{2}{ }^{\text {homo }}$ values are summarized in Table 3 .

Table S1. Detailed experimental conditions of REDOR (REAPDOR) NMR experiments

\begin{tabular}{cccccccc}
\hline & $\begin{array}{c}\text { MAS NMR } \\
\text { probe/mm }\end{array}$ & \multicolumn{2}{c}{ resonance frequency } \\
Experiments & \multicolumn{2}{c}{$\begin{array}{c}\mathrm{MHz} \\
\text { S-spin }\end{array}$} & I-spin & rate/kHz & $\begin{array}{c}\text { relaxation } \\
\text { delay/s }\end{array}$ & \multicolumn{2}{c}{$\pi$ pulse length/ $\mu$ s } \\
\hline${ }^{27} \mathrm{Al}\left\{{ }^{19} \mathrm{~F}\right\}$ & 2.5 & 130.3 & 470.5 & 24 & 0.5 & 4.6 & 4.4 \\
${ }^{19} \mathrm{~F}\left\{{ }^{27} \mathrm{Al}\right\}$ & 2.5 & 470.5 & 130.3 & 24 & 10 & 4.4 & $-^{\mathrm{a}}$ \\
${ }^{19} \mathrm{~F}\left\{{ }^{23} \mathrm{Na}\right\}$ & 2.5 & 470.5 & 132.3 & 24 & 10 & 4.4 & 4.6 \\
${ }^{23} \mathrm{Na}\left\{{ }^{19} \mathrm{~F}\right\}$ & 2.5 & 132.3 & 470.5 & 24 & 0.5 & 4.6 & 4.4 \\
\hline
\end{tabular}




\begin{tabular}{lllllllll}
\hline${ }^{19} \mathrm{~F}\left\{{ }^{139} \mathrm{La}\right\}$ & 2.5 & 470.5 & 70.6 & 24 & 10 & 4 & $-^{\mathrm{a}}$ \\
\hline
\end{tabular}

adiabatic pulse of 13.89 (1/3 rotor period) was employed.
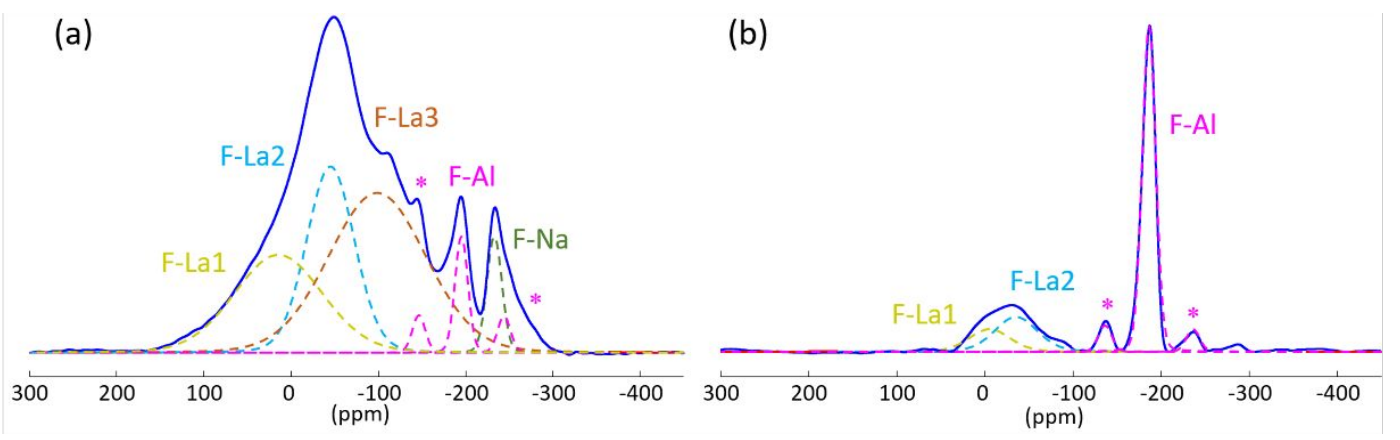

Figure S1. Deconvolution of ${ }^{19}$ F MAS spectra of S10A3 (a) and S22A1 (b) glasses.

Table S2. Deconvolution parameters of ${ }^{19} \mathrm{~F}$ MAS spectra of all the samples and the calculated $\boldsymbol{R}_{\mathrm{F}-\mathrm{M}}$ values

\begin{tabular}{|c|c|c|c|c|c|c|}
\hline \multicolumn{2}{|c|}{ Samples } & $\begin{array}{c}\delta_{C S^{i s o}} \\
(\mathrm{ppm}) \\
( \pm 0.5 \\
\mathrm{ppm}) \\
\end{array}$ & $\begin{array}{c}F W H M \\
(\mathrm{ppm}) \\
( \pm 0.5 \\
\mathrm{ppm}) \\
\end{array}$ & \multicolumn{2}{|c|}{$\begin{array}{l}\text { Fraction } \\
(\%)( \pm 10 \%)\end{array}$} & $\begin{array}{r}R_{\mathrm{F}-\mathrm{M}} \\
( \pm 0.2)\end{array}$ \\
\hline \multirow[t]{5}{*}{ S10A1 } & F-La1 & 23.8 & 122.5 & 26.0 & $87.3^{\mathrm{a}}$ & 8.7 \\
\hline & $\mathrm{F}-\mathrm{La} 2$ & -36.0 & 67.5 & 27.5 & & \\
\hline & $\mathrm{F}-\mathrm{La} 3$ & -92.5 & 131.7 & 33.8 & & \\
\hline & $\mathrm{F}-\mathrm{Al}$ & -196.2 & 17.6 & 10.1 & & 1.0 \\
\hline & $\mathrm{F}-\mathrm{Na}$ & -233.0 & 20.3 & 2.6 & & \\
\hline \multirow[t]{5}{*}{$\mathrm{S} 10 \mathrm{~A} 2$} & F-La1 & 20.8 & 119.5 & 21.7 & $86.7^{\mathrm{a}}$ & 8.7 \\
\hline & $\mathrm{F}-\mathrm{La} 2$ & -36.0 & 65.9 & 20.8 & & \\
\hline & $\mathrm{F}-\mathrm{La} 3$ & -90.7 & 131.7 & 44.2 & & \\
\hline & $\mathrm{F}-\mathrm{Al}$ & -189.2 & 17.6 & 8.5 & & 0.9 \\
\hline & $\mathrm{F}-\mathrm{Na}$ & -228.0 & 20.3 & 4.8 & & \\
\hline \multirow[t]{5}{*}{$\mathrm{S} 10 \mathrm{~A} 3$} & F-La1 & 14.8 & 119.5 & 22.9 & $88.6^{\mathrm{a}}$ & 8.9 \\
\hline & F-La2 & -45.0 & 64.9 & 23.3 & & \\
\hline & $\mathrm{F}-\mathrm{La} 3$ & -98.7 & 131.7 & 42.4 & & \\
\hline & $\mathrm{F}-\mathrm{Al}$ & -195.2 & 17.6 & 6.7 & & 0.7 \\
\hline & $\mathrm{F}-\mathrm{Na}$ & -233.0 & 20.3 & 4.7 & & \\
\hline \multirow[t]{3}{*}{$\mathrm{S} 22 \mathrm{~A} 1$} & F-La1 & -5.0 & 55.5 & 12.8 & $33.0^{\mathrm{a}}$ & 3.3 \\
\hline & $\mathrm{F}-\mathrm{La} 2$ & -35.3 & 57.3 & 20.2 & & \\
\hline & $\mathrm{F}-\mathrm{Al}$ & -186.0 & 17.9 & 67.0 & & 1.5 \\
\hline \multirow[t]{3}{*}{$\mathrm{S} 22 \mathrm{~A} 2$} & $\mathrm{LaOF}$ & -20.3 & 37.2 & 70.3 & & 7.0 \\
\hline & $\mathrm{F}-\mathrm{Al}$ & -186.2 & 19.6 & 27.4 & & 0.6 \\
\hline & $\mathrm{F}-\mathrm{Na}$ & -220.6 & 19.3 & 2.3 & & \\
\hline
\end{tabular}

${ }^{a}$ The sum of the content of F-La1+ F-La2 (+ F-La3)

Table S3. ${ }^{23} \mathrm{Na}$ isotropic chemical shifts $\delta_{C S}{ }^{i s o}$, second-order quadrupolar effects $(S O Q E)$ and efficiency factor $f$ measured in the glasses and glass ceramics

\begin{tabular}{rcccc}
\hline Samples & $\begin{array}{c}\delta_{C S^{i s o}}(\mathrm{ppm}) \\
( \pm 0.3 \mathrm{ppm})\end{array}$ & $\begin{array}{c}\text { SOQE }(\mathrm{MHz}) \\
( \pm 0.3 \mathrm{MHz})\end{array}$ & $\begin{array}{c}f \\
( \pm 0.001)\end{array}$ \\
\hline S10A1 & -7.5 & 2.1 & 0.094 \\
S10A2 & & -7.5 & 2.1 & 0.096 \\
S10A3 & -4.2 & 2.2 & 0.087 \\
S10A3 650 $\mathrm{C} 10 \mathrm{~h}$ & Site 1 & -4.6 & 2.3 & 0.083 \\
& Site 2 & -14.5 & 1.2 & 0.171 \\
S22A1 & & -9.0 & 2.1 & 0.092 \\
\hline
\end{tabular}




\begin{tabular}{lllll}
\hline S22A2 & Site 1 & -8.9 & 1.8 & 0.095 \\
& Site 2 & -16.0 & 1.3 & 0.132 \\
\hline
\end{tabular}

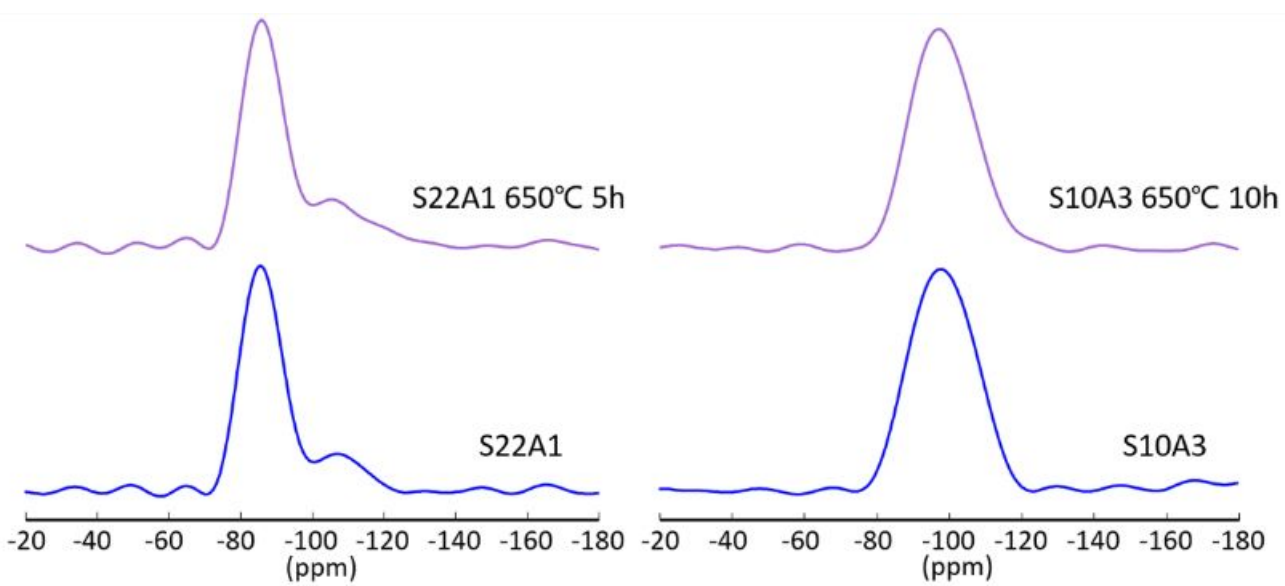

Figure S2. Comparison between the ${ }^{29} \mathrm{Si}$ MAS spectra of glasses and glass ceramics.

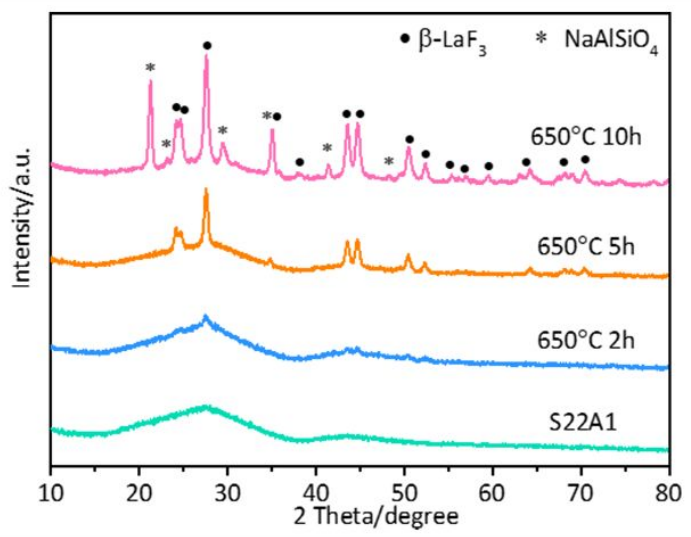

Figure S3. The XRD patterns of S22A1 glass and corresponding glass ceramics heat-treated at $650^{\circ} \mathrm{C}$ for different times $(2 \mathrm{~h}, 5 \mathrm{~h}$, and $10 \mathrm{~h})$.
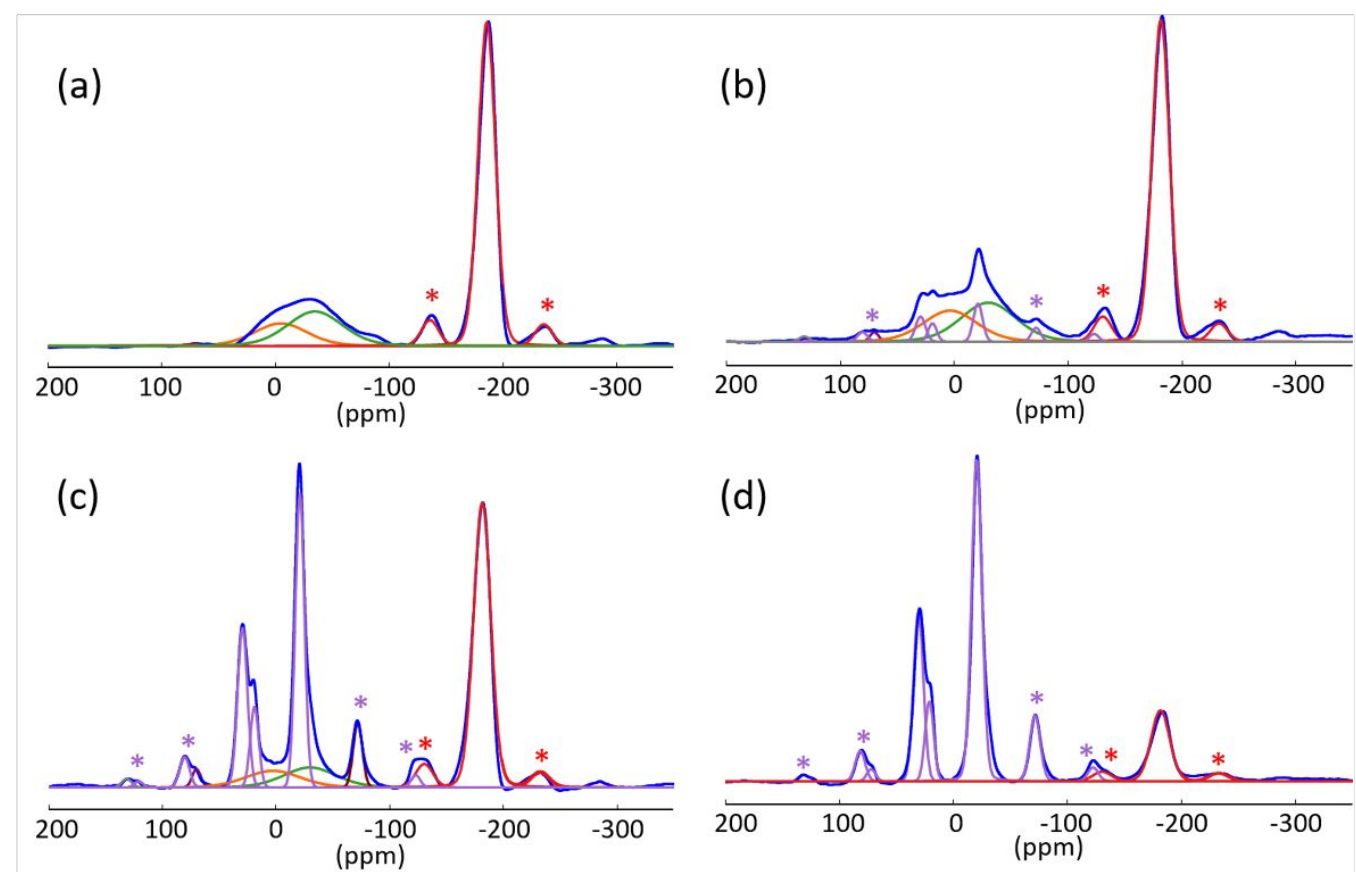
Figure S4. Deconvolution results of ${ }^{19} \mathrm{~F}$ MAS spectra of S22A1 glass (a) and corresponding glass ceramics heated at $650^{\circ} \mathrm{C}$ for different times $2 \mathrm{~h}(\mathrm{~b}), 5 \mathrm{~h}(\mathrm{c})$, and $10 \mathrm{~h}$ (d). The purple, orange, green, and red lines denote $\mathrm{LaF}_{3}, \mathrm{~F}-\mathrm{La} 1, \mathrm{~F}-\mathrm{La} 2$, and F-Al linkages, respectively. All the spinning sidebands are indicated by colored asterisks.

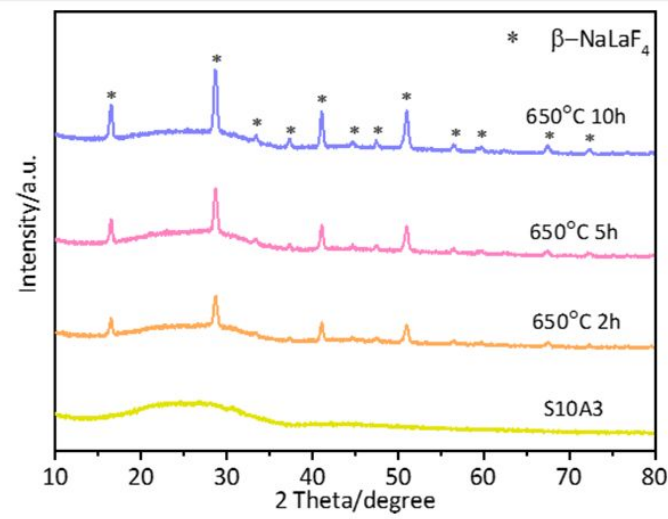

Figure S5. The XRD patterns of S10A3 glass and corresponding glass ceramics heat-treated at $650^{\circ} \mathrm{C}$ for different times $(2 \mathrm{~h}, 5 \mathrm{~h}$, and $10 \mathrm{~h})$.
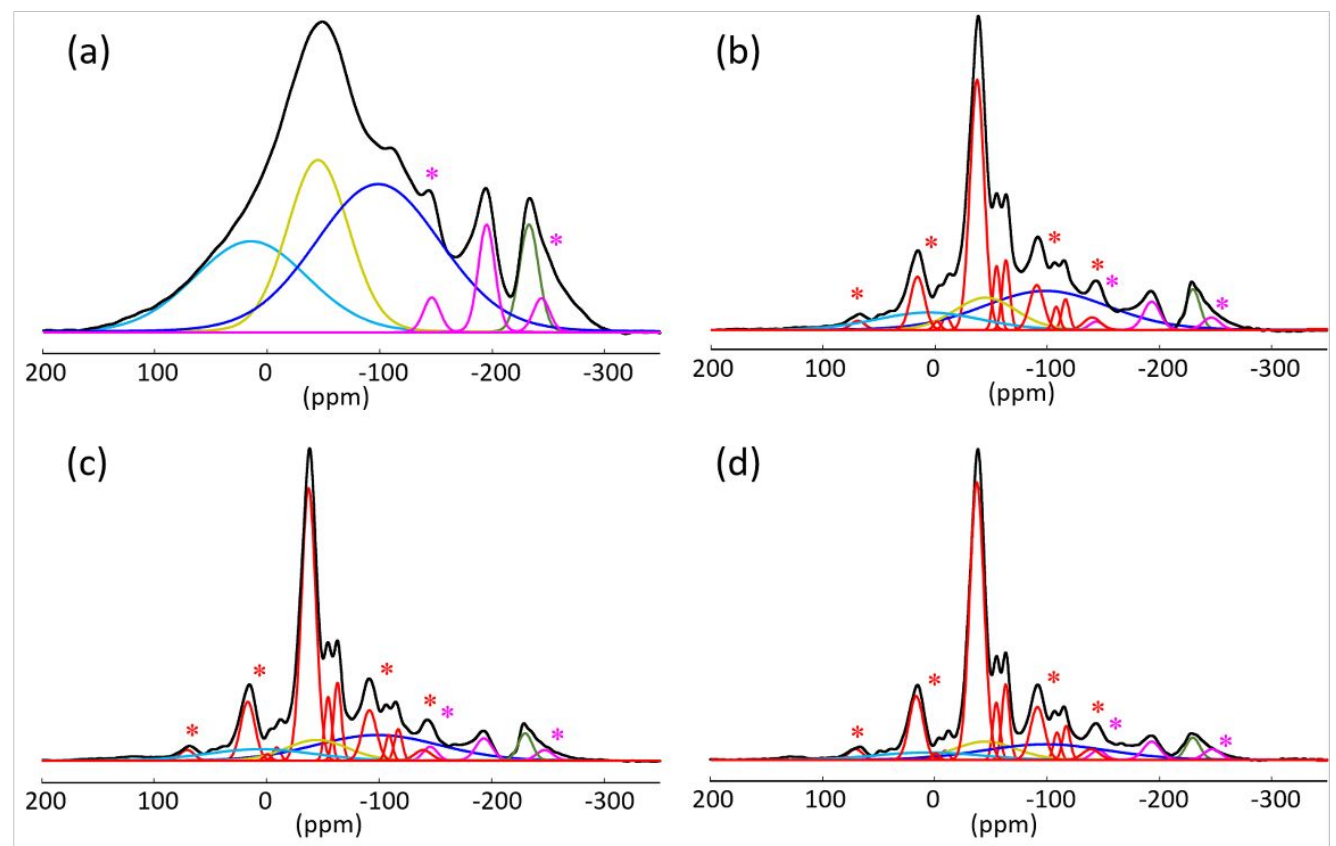

Figure S6. Deconvolution results of ${ }^{19} \mathrm{~F}$ MAS NMR spectra of S10A3 glass (a) and corresponding glass ceramics heated at $650{ }^{\circ} \mathrm{C}$ for different times $2 \mathrm{~h}(\mathrm{~b}), 5 \mathrm{~h}$ (c), and $10 \mathrm{~h}$ (d). The red, wathet, yellow, blue, and pink lines denote NaLaF 4 , F-La1, F-La2, F-La3, and F-Al linkages, respectively. All the spinning sidebands are indicated by coloured asterisks. 
(a)

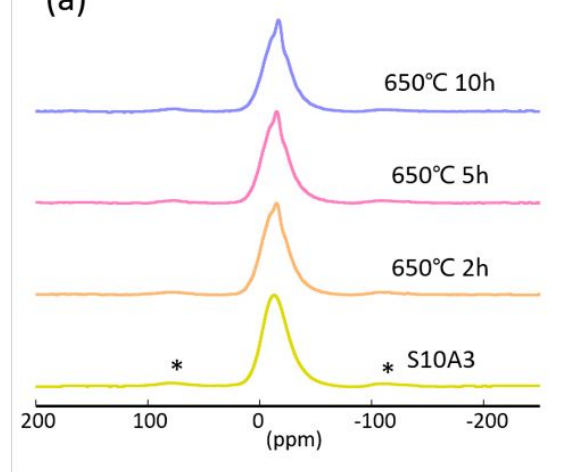

(b)

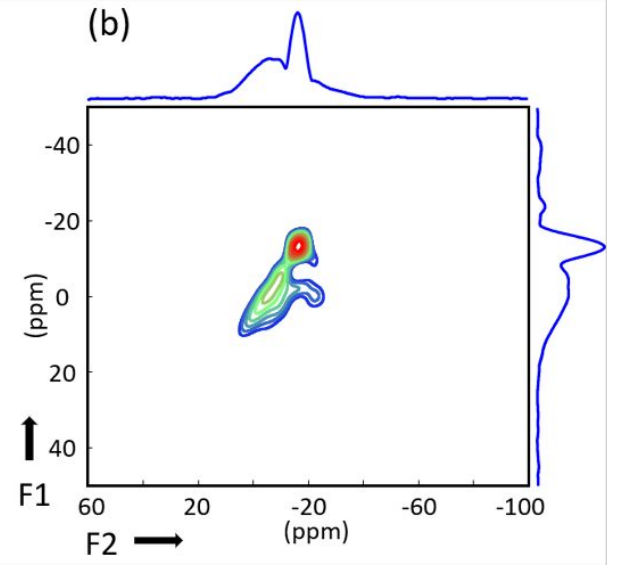

Figure S7. (a) ${ }^{23} \mathrm{Na}$ MAS spectra of S10A3 glass and corresponding glass ceramics heated at $650^{\circ} \mathrm{C}$ for different time $(2 \mathrm{~h}, 5 \mathrm{~h}$, and $10 \mathrm{~h})$. Asterisks denote spinning sidebands. (b) ${ }^{23} \mathrm{Na}$ TQMAS spectrum of S10A3 glass ceramic heated at $650^{\circ} \mathrm{C}$ for $10 \mathrm{~h}$.

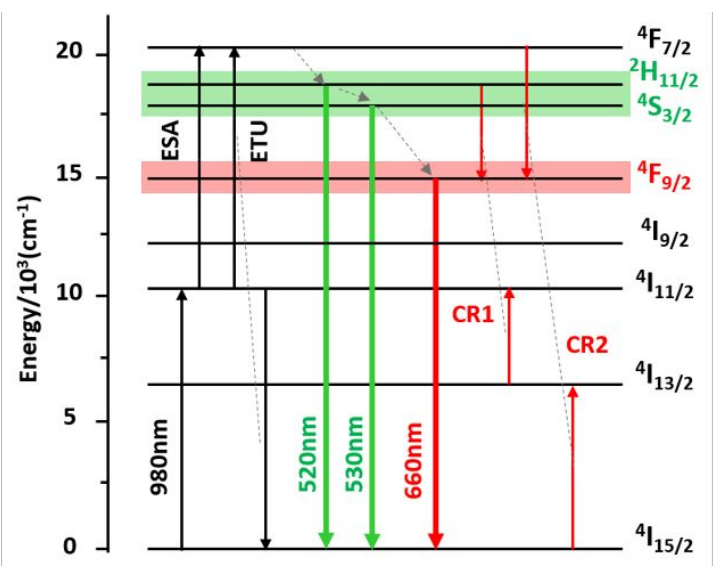

Figure S8. Energy level diagrams of $\mathrm{Er}^{3+}$ ions and the possible UC mechanisms in GC samples under $980 \mathrm{~nm}$ laser excitation. Firstly, the ${ }^{4} \mathrm{~F}_{7 / 2}$ energy level is populated by excited state absorption (ESA) and energy transfer upconversion (ETU) processes. ${ }^{18}$ Then the electrons in ${ }^{4} \mathrm{~F}_{7 / 2}$ level are transferred to ${ }^{2} \mathrm{H}_{11 / 2}$ and ${ }^{4} \mathrm{~S}_{3 / 2}$ levels by non-radiative relaxation process, leading to intense green luminescence emission. The weak red luminescence is attributed to weak population of the ${ }^{4} \mathrm{~F}_{9 / 2}$ level. The ${ }^{4} \mathrm{~F}_{9 / 2}$ level can be populated by non-radiative relaxation from the electrons in ${ }^{4} \mathrm{~S}_{3 / 2}$ levels, and the cross-relaxation processes (CR1: $\left.{ }^{2} \mathrm{H}_{11 / 2},{ }^{4} \mathrm{I}_{13 / 2} \rightarrow{ }^{4} \mathrm{~F}_{9 / 2},{ }^{4} \mathrm{I}_{11 / 2} ; \mathrm{CR} 2:{ }^{4} \mathrm{~F}_{7 / 2},{ }^{4} \mathrm{I}_{15 / 2} \rightarrow{ }^{4} \mathrm{~F}_{9 / 2},{ }^{4} \mathrm{I}_{13 / 2}\right) .{ }^{19}$ 


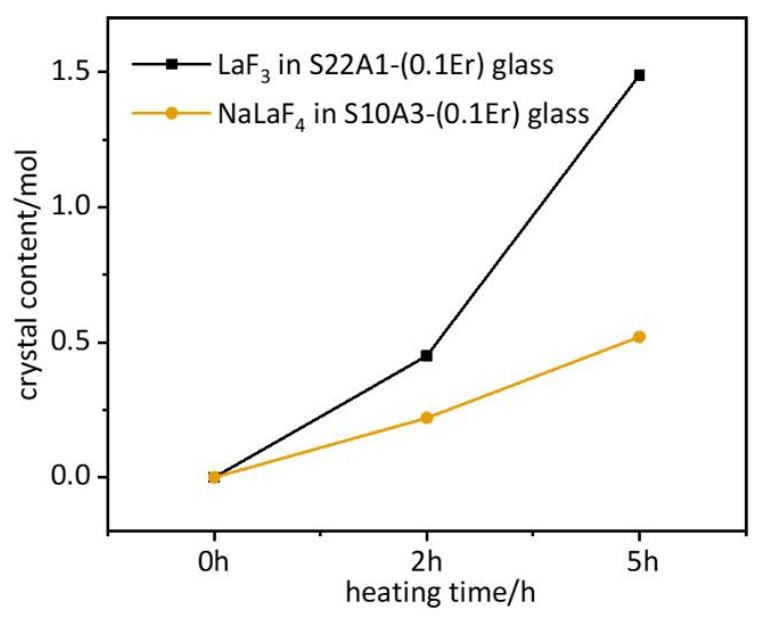

Figure S9. The content evolution of fluoride crystals in S22A1-(0.1Er) and S10A3-(0.1Er) glasses.

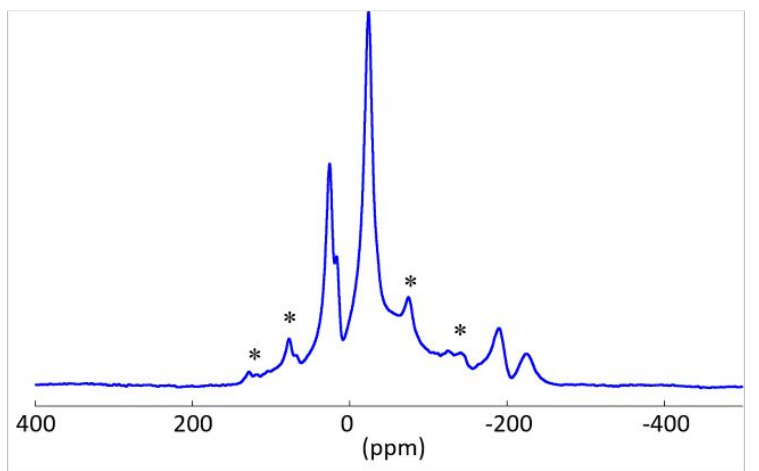

Figure $\mathrm{S} 10 .{ }^{19} \mathrm{~F}$ MAS spectrum of $\mathrm{S} 10 \mathrm{~A} 1$ glass heated at $700^{\circ} \mathrm{C}$ for $10 \mathrm{~h}$.
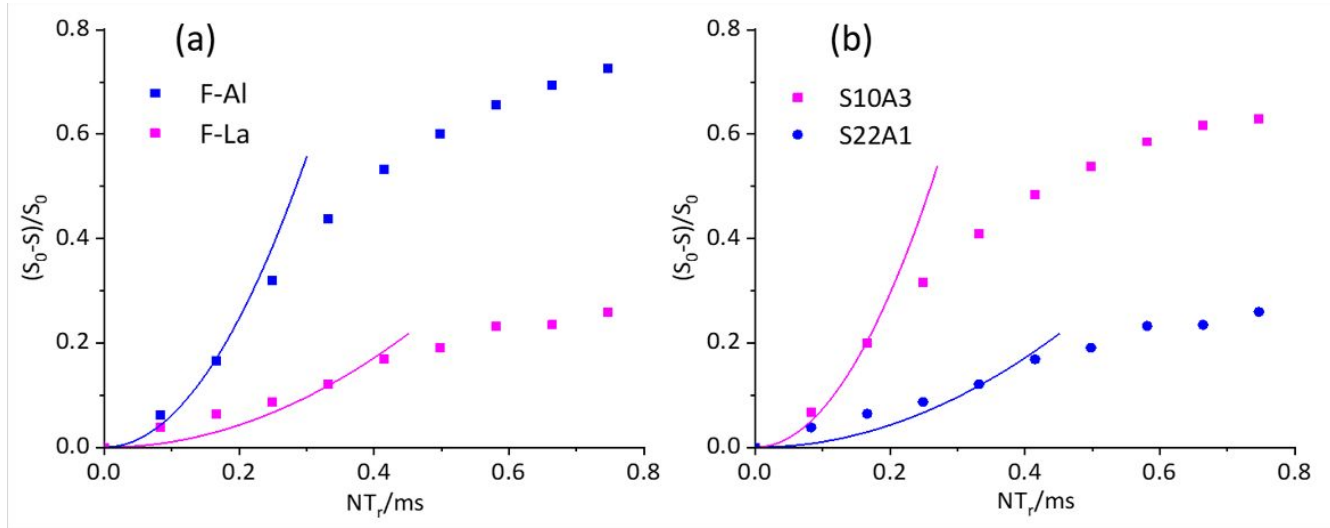

Figure S11. (a) ${ }^{19} \mathrm{~F}\left\{{ }^{23} \mathrm{Na}\right\}$ REDOR dephasing curves of S22A1 glasses. The site-resolved results were obtained by separately integrating the narrow regions of $\mathrm{F}-\mathrm{La}$ and $\mathrm{F}-\mathrm{Al}$ linkages. (b) ${ }^{19} \mathrm{~F}\left\{{ }^{23} \mathrm{Na}\right\}(\mathrm{F}-\mathrm{La})$ REDOR dephasing curves of S10A3 and S22A1 glasses. 


\section{References}

1. O'Dell, L. A.; Schurko, R. W. QCPMG using adiabatic pulses for faster acquisition of ultra-wideline NMR spectra. Chem. Phys. Lett. 2008, 464, 97-102.

2. Gullion, T.; Schaefer, J. Rotational-Echo Double-Resonance NMR. J. Magn. Reson. 1989, 81, 196-200.

3. Gullion, T. Measurement of heteronuclear dipolar interactions by rotational-echo, double-resonance nuclear magnetic resonance. Magn. Reson. Rev. 1997, 17, 83-131.

4. Pan, Y.; Gullion, T.; Schaefer, J. Determination of C-N Internuclear Distances by Rotational-Echo Double-Resonance NMR of Solids. J. Magn. Reson. 1990, 90, 330-340.

5. Bertmer, M.; Eckert, H. Dephasing of spin echoes by multiple heteronuclear dipolar interactions in rotational echo double resonance NMR experiments. Solid State Nucl. Magn. Reson. 1999, 15, 139-152.

6. Garbow, J. R.; Gullion, T. The Importance of Precise Timing in Pulsed, Rotor-Synchronous MAS NMR. Chem. Phys. Lett. 1992, $192,71-76$.

7. Schmidt, A.; Mckay, R. A.; Schaefer, J. Internuclear Distance Measurement between Deuterium (I = 1) and a Spin-1/2 Nucleus in Rotating Solids. J. Magn. Reson. 1992, 96, 644-650.

8. Eckert, H.; Elbers, S.; Epping, J. D.; Janssen, M.; Kalwei, M.; Strojek, W.; Voigt, U. Dipolar solid state NMR approaches towards medium-range structure in oxide glasses. Top. Curr. Chem. 2005, 246, 195-233.

9. Strojek, W.; Kalwei, M.; Eckert, H. Dipolar NMR strategies for multispin systems involving quadrupolar nuclei: ${ }^{31} \mathrm{P}\left\{{ }^{23} \mathrm{Na}\right\}$ rotational echo double resonance (REDOR) of crystalline sodium phosphates and phosphate glasses. J. Phys. Chem. B 2004, 108, 7061-7073.

10. Bak, M.; Rasmussen, J. T.; Nielsen, N. C. SIMPSON: A general simulation program for solid-state NMR spectroscopy. J. Magn. Reson. 2000, 147, 296-330.

11. Vanvleck, J. H. The Dipolar Broadening of Magnetic Resonance Lines in Crystals. Phys. Rev. 1948, 74, 1168-1183.

12. Chopin, L.; Vega, S.; Gullion, T. A MAS NMR method for measuring ${ }^{13} \mathrm{C}-{ }^{17} \mathrm{O}$ distances. J. Am. Chem. Soc. 1998, 120, $4406-4409$.

13. Gullion, T. Detecting ${ }^{13} \mathrm{C}-{ }^{17} \mathrm{O}$ dipolar interactions by rotational-echo, adiabatic-passage, double-resonance NMR. J. Magn. Reson. 1995, 117, 326-329.

14.Ba, Y.; Kao, H.-M.; Grey, C. P.; Chopin, L.; Gullion, T. Optimizing the ${ }^{13} \mathrm{C}-{ }^{14} \mathrm{~N}$ REAPDOR NMR Experiment: A Theoretical and Experimental Study. J. Magn. Reson. 1998, 133, 104-114.

15. Medek, A.; Harwood, J. S.; Frydman, L. Multiple-quantum magic-angle spinning NMR: A new method for the study of quadrupolar nuclei in solids. J. Am. Chem. Soc. 1995, 117, 12779-12787.

16. Amoureux, J. P.; Fernandez, C.; Steuernagel, S. Z filtering in MQMAS NMR. J. Magn. Reson., Ser A 1996, 123, 116-118.

17.Lathrop, D., \& Eckert, H. Structural models for non-oxide chalcogenide glasses. Atomic distribution and local order in the system phosphorus-selenium studied by phosphorus-31 dipolar NMR spectroscopy. J. Am. Chem. Soc. 1989, 111, 3536-3541.

18. van der Ziel, J. P.; Van Uitert, L. G.; Grodkiewicz, W. H.; Mikulyak, R. M. 1.5- $\mu \mathrm{m}$ infrared excitation of visible luminescent in $\mathrm{Y}_{1-\mathrm{x}} \mathrm{Er}_{\mathrm{x}} \mathrm{F}_{3}$ and $\mathrm{Y}_{1-\mathrm{x}-\mathrm{y}} \mathrm{Er}_{\mathrm{x}} \mathrm{Tm}_{\mathrm{y}} \mathrm{F}_{3}$ via resonant-energy transfer. J. Appl. Phys. 1986, 60, 4262-4267.

19. Balda, R.; Fernández, J.; Arriandiaga, M. A.; Fdez-Navarro, J. M. Infrared to visible upconversion of $\mathrm{Er}^{3+}$ and $\mathrm{Er}^{3+} / \mathrm{Yb}^{3+} \mathrm{codoped} \mathrm{lead-}^{-}$ niobium-germanate glasses. Opt. Mater. 2004, 25, 157-163. 